\title{
A percepção de professores e alunos do ensino médio sobre a atividade estudo de caso
}

\author{
The perception of high school teachers and students \\ about the case study teaching activity
}

Fernanda Luiza Faria ${ }^{1}$ • Ivoni Freitas-Reis ${ }^{1}$

\begin{abstract}
Resumo: O estudo investiga a potencialidade da Estratégia de Ensino Estudo de Caso (EEEC) para o ensino de Química, no Ensino Médio. Para isso, a EEEC foi aplicada por três professores de Química de uma escola pública da cidade de Juiz de Fora, Minas Gerais. Como instrumentos de pesquisa foram utilizados: observação das aulas, aplicação de questionário aos estudantes e realização de entrevista semiestruturada com os professores. Os dados construídos foram interpretados mediante Análise de Conteúdo. Na percepção dos professores e estudantes investigados, a EEEC é uma proposta de ensino favorável e significativa para o Ensino Médio. Esses sujeitos destacaram: participação ativa e crítica do estudante, trabalho em grupo, aquisição de conhecimentos científicos, aproximação do conteúdo com a realidade do estudante, estímulo ao desenvolvimento de habilidades importantes como leitura, argumentação, comunicação oral, entre outros. Apontaram dificuldades para aplicação da EEEC, como o tempo e a falta de recursos para a pesquisa.
\end{abstract}

Palavras-chave: Resolução de problemas. Estudo de caso. Ensino médio. Ensino de química.

\begin{abstract}
The focal point of this research was the potentiality of the Case Study Teaching Strategy (CSTS) for teaching High School Chemistry. To do this, CSTS was applied by three Chemistry teachers in a public school in Brazil. As research instruments, we used classroom observation, application of a questionnaire to the students and a semi-structured interview with the teachers. The results indicated that, according to teachers and students, CSTS is a favourable and significant teaching tool for High School. These subjects pointed out the emphasis in the active and analytical participation of students, group work, acquiring of different scientific knowledge, approaching the content from the student's experience, stimulation of the development of important abilities by the students, such as reading, argumentation, oral communication, among others. They also pointed out difficulties involved in the application of CSTS, such as time and the lack of resources for the research.
\end{abstract}

Keywords: Problem Solving. Case Study. High School. Chemical Education.

\footnotetext{
${ }^{1}$ Universidade Federal de Juiz de Fora, Departamento de Química, Juiz de Fora, MG, Brasil.

E-mail: <fernanda.ldefaria@gmail.com>.
} 


\section{Introdução}

Os conhecimentos científicos devem ser trabalhados em sala de aula com a finalidade de contribuir para a formação de cidadãos mais ativos, críticos e conscientes. O Ensino de Ciências deve dar condições para promover uma cultura científica ao educando (BRASIL, 2002). Todavia, o Ensino das Ciências na Educação Básica brasileira tem mostrado uma grande defasagem. O Ensino de Química, por exemplo, tem tido como foco a "transmissão de conhecimentos", memorização, conceitos sem relação com a origem científica e a realidade do aluno, ao invés de ser mais uma forma de auxiliar a compreensão da realidade que nos cerca (BRASIL, 2002, 2006).

Ao longo dos anos, documentos oficiais, como os Parâmetros Curriculares Nacionais para o Ensino Médio (PCNEM), têm trazido à discussão propostas para o desenvolvimento de um ensino menos fragmentado e linear, almejando atividades mais interdisciplinares e abordagens transdisciplinares. Todavia, como destacam as Orientações Curriculares Nacionais, essa mudança não tem sido efetiva nas salas de aula brasileiras. Assim, esses documentos reforçam a importância das disciplinas que compõem a área das Ciências da Natureza a estabelecerem um diálogo entre si e, para isso, torna-se essencial a abordagem de situações que retratam a realidade, a vivência do estudante, os fenômenos naturais e artificiais e as aplicações tecnológicas (BRASIL, 2006).

Nas Orientações Curriculares Nacionais (OCN) para o Ensino Médio (BRASIL, 2006) tem-se destaque para a relevância do enfoque Ciência-Tecnologia-Sociedade (CTS), principalmente na abordagem do saber químico, como pode ser notado no trecho a seguir:

A discussão de aspectos sociocientíficos articuladamente aos conteúdos químicos e aos contextos é fundamental, pois propicia que os alunos compreendam o mundo social em que estão inseridos e desenvolvam a capacidade de tomada de decisão com maior responsabilidade, na qualidade de cidadãos, sobre questões relativas à Química e à Tecnologia, e desenvolvam também atitudes e valores comprometidos com a cidadania planetária em busca da preservação ambiental e da diminuição das desigualdades econômicas, sociais, culturais e éticas. Ao se discutirem aspectos sociocientíficos, vão emergir em sala de aula diferentes pontos de vista, que deverão ser problematizados mediante argumentos coletivamente construídos, com encaminhamentos de possíveis respostas a problemas sociais relativos à Ciência e à Tecnologia. (BRASIL, 2006, p. 119).

Avaliações externas ou exames nacionais, como o Exame Nacional do Ensino Médio (ENEM), mostram que os alunos não têm conseguido realizar questões que exijam competências e habilidades, como leitura e interpretação, comparação e fundamentação de respostas (BRASIL, 2006). A nova matriz do ENEM aponta cinco eixos cognitivos que devem ser instigados em todas as áreas do conhecimento. São elas: dominar linguagens, compreender fenômenos, enfrentar situações-problema, construir argumentação, elaborar propostas (BRASIL, 2009). Desta forma, tem-se cada vez mais reforçado a importância de um currículo que permita o desenvolvimento de competências básicas.

Frente a esse contexto, fica claro que para o ensino de Química, foco desta pesquisa, atender aos aspectos mencionados anteriormente, é preciso uma mudança na prática pedagógica adotada na maioria das escolas públicas do Brasil. Uma maneira significativa de contribuir para 
A percepção de professores e alunos do ensino médio ...

essa mudança é levar para o espaço escolar propostas de ensino com abordagens diferenciadas. Essas estratégias devem buscar a problematização e, principalmente, devem permitir que os educandos desempenhem um papel mais ativo num espaço do qual eles também fazem parte. $\mathrm{O}$ presente estudo retrata uma proposta de ensino baseada na resolução de casos, que dá condições para que esses aspectos sejam enfatizados: a Estratégia de Ensino por Estudo de Caso (EEEC).

A EEEC é uma variante do método Aprendizagem Baseada em Problemas, conhecido internacionalmente como Problem Based Learning (PBL). Esse método teve origem no final dos anos 1960 na Escola de Medicina da Universidade de McMaster, em Ontário, no Canadá. Ele surgiu com o intuito de permitir que seus alunos tivessem contato com problemas reais da área ainda no período da graduação (HERREID, 1997).

A EEEC é adotada no Brasil prioritariamente nos cursos de Medicina, Direito, Administração, Economia e em menor proporção nos cursos de Ciências, no Ensino Superior. No Ensino Médio o uso da EEEC é ainda mais reduzido (SÁ; QUEIROZ, 2010).

A EEEC estrutura-se em casos com uma problemática. Trata-se de narrativas com situações hipotéticas ou verdadeiras sobre personagens que vivem dilemas e requerem uma tomada de decisão. Os casos nem sempre apresentam uma única solução, pois há o envolvimento da narrativa com questões sociais, emocionais, econômicas, éticas, políticas, entre outras (HERREID, 1997).

Educadores e educandos possuem na EEEC posicionamentos distintos. O educando tem um papel mais ativo, sendo responsável pelo desfecho da narrativa. Ele deve encontrar uma causa para o problema e propor uma solução a qual julgue mais viável. Para isso, ele levanta hipóteses, pesquisa, analisa as alternativas, chega a uma tomada de decisão e, por fim, usa da argumentação e persuasão para convencer os demais colegas de classe sobre a sua decisão.

O professor tem o papel de orientar o processo de resolução e mediar as discussões geradas, instigando o debate e permitindo que relações entre o tema e o conteúdo específico façam sentido para o aluno.

A EEEC pode ainda ser trabalhada sob o enfoque CTS, uma vez que compartilha dos anseios dessa abordagem de ensino, a qual busca a formação de cidadãos críticos enquanto possibilita aos estudantes desenvolverem uma postura de tomada de decisão (SANTOS; SCHNETZLER, 2010). Além disso, essa atividade pode ser também estabelecida como uma proposta de ensino por situação-problema, visto que traz aspectos bem semelhantes. Isto por que:

[Situação-problema] pede um posicionamento, pede um arriscar-se, coordenar fatores em um contexto delimitado, com limitações que nos desafiam a superar obstáculos, a pensar em um outro plano ou nível. Trata-se, portanto, de uma alteração criadora de um contexto que problematiza, perturba, desequilibra. (MACEDO, 2002, p. 115).

Logo, características marcantes de um ensino por situação-problema, como a mobilização de recursos, a organização de ideias, a busca de uma solução, a chegada a uma tomada de decisão, dentre outras, podem ser encontradas na EEEC.

Trabalhos da literatura destacam que estratégias CTS, bem como o ensino por situações-problemas, possibilitam que os estudantes desenvolvam competências e habilidades importantes. Diante disso, a EEEC demonstra também potencial para este desenvolvimento (BRASIL, 2006; MACEDO, 2002; SÁ, 2006; SANTOS; MORTIMER, 2002). 
As situações de estudo (SE) têm sido destaque em alguns trabalhos para o Ensino de Ciências, demonstrando potencial para uma abordagem integradora do conhecimento científico, a partir de temas problematizadores e contextualizados (GEHLEN; MALDANER; DELIZOICOV, 2012; MALDANER; ZANON, 2004; RITTER; MALDANER, 2015). A SE é:

Uma orientação para o ensino e a formação escolar que, de acordo com nosso pensamento, supera visões anteriores na medida em que articula saberes e conteúdos de Ciências entre si e com saberes cotidianos trazidos das vivências dos alunos fora da escola, permitindo uma abordagem com característica interdisciplinar, intercomplementar e transdisciplinar. (MALDANER; ZANON, 2004, p. 44).

A EEEC é uma proposta de ensino que pode ser abordada no Ensino das Ciências a fim de contribuir também para essa percepção integradora das Ciências. Nessa perspectiva, traz aspectos semelhantes à SE, pois permite a utilização de temáticas mais contextualizadas nas narrativas, na vinculação da resolução do problema e na tomada de decisão frente a diferentes áreas das Ciências.

Quando se discute sobre a utilização de propostas de ensino diferenciadas em sala de aula, há o questionamento se os docentes estão preparados para isso. Decerto, o professor tem um papel muito importante na adoção de qualquer proposta educacional. Santos e Mortimer (2002) trazem discussões acerca da necessidade de mudanças significativas na prática e nas concepções pedagógicas do docente, bem como da importância da sua formação inicial e continuada, contestando que não há como desenvolver novos modelos curriculares sem envolver os professores. Maldaner (2006) fala um pouco sobre essa mudança na prática pedagógica, citando o professor de Química:

A melhor forma de mudar a prática nas aulas seria a produção conjunta de conhecimentos profissionais que pudessem ser utilizados imediatamente pelo professor e que fossem de conhecimento escolar importante de Química e de interesse do aluno. (MALDANER, 2006, p. 29).

Carvalho e Gil-Pérez (2011) destacam que muitos docentes não tiveram uma formação adequada e que nem mesmo estão cientes das suas limitações. Esses autores mencionam ainda a pequena familiaridade destes profissionais com as contribuições da pesquisa científica e as suas inovações didáticas. Assim, fica claro que, para que mudanças ocorram no ambiente escolar, os docentes devem estar dispostos a mudar a sua prática pedagógica.

Concordamos com Santos et al. (2006) quando afirmam que os processos de formação continuada devem levar em questão os envolvidos com a educação, conhecendo o contexto e a cultura escolar. Além disso, torna-se imprescindível que sejam conhecidas as concepções do docente e do discente. As atividades desenvolvidas, para este tipo de formação, devem focar a reflexão sobre a prática pedagógica, trabalhando junto ao educador e não para ele.

Complementamos ainda que não basta apresentar propostas de ensino para os educadores, estes profissionais precisam ter a experiência de vivenciar a atividade e opinar sobre ela, de forma que eles conheçam as contribuições da estratégia, mas também apontem obstáculos 
A percepção de professores e alunos do ensino médio ...

para a sua abordagem. Diante disso, nosso trabalho traz como diferencial a preocupação em apresentar essa proposta para professores da Educação Básica de forma que eles participem ativamente do processo, construindo e aplicando seus próprios casos e possam, posteriormente, adotar mais vezes a estratégia em sala de aula.

Assim, essa pesquisa trouxe como questionamento: A EEEC pode ser adotada no Ensino Médio, de forma satisfatória, na percepção dos principais envolvidos nesse ambiente?

\section{Metodologia}

O percurso metodológico adotado tem natureza qualitativa, como destacam Bogdan e Biklen (1994), sendo um processo descritivo, no qual o caminho é mais relevante que o produto. Os sujeitos desta pesquisa foram três professores de Química e os seus respectivos alunos do Ensino Médio, cada qual com uma turma, em três escolas públicas da cidade de Juiz de Fora, no estado de Minas Gerais, Brasil. A seleção desses educadores aconteceu a partir de um minicurso realizado pelas pesquisadoras deste trabalho. O minicurso ocorreu com a finalidade de divulgar a EEEC para professores de Química do município.

Os professores receberam os nomes fictícios Pedro, Regina e Carla, e essa nomeação permaneceu no decorrer de toda a pesquisa. Os professores Pedro e Regina optaram por trabalhar com turmas do $3^{\circ}$ ano, a professora Carla com uma turma do $2^{\circ}$ ano do Ensino Médio.

Após a seleção dos três docentes, eles produziram um cronograma de aplicação da EEEC e construíram casos investigativos para serem adotados na turma de alunos escolhida. Almejavase que esses educadores vivenciassem, como um todo, o processo de aplicação da atividade. Os professores ficaram livres para a escolha do tema, conteúdo e número de casos a serem produzidos.

Após a construção dos casos, teve início o trabalho com a EEEC nas referidas turmas. Cada educador detalhou o funcionamento da atividade e, em grupos, a turma recebeu o caso. Cada grupo deveria buscar soluções plausíveis e, posteriormente, apresentar frente à classe o trabalho realizado. O caminho adotado pelos alunos foi registrado em um diário de bordo, o qual o professor acompanhou semanalmente. O professor ficou responsável por instigar e mediar as possíveis discussões geradas pelo tema, bem como, dar condições para que o tópico abordado e o conteúdo trabalhado apresentassem estreita relação e fizessem sentido para toda a turma.

Diante do percurso detalhado, para a construção do corpus de análise foi utilizado três instrumentos de pesquisa: a observação, o questionário e a entrevista semiestruturada. O questionário, aplicado aos alunos, visava investigar a percepção destes em relação ao tema discutido, ao formato de grupos adotado e às demais características da EEEC. Questionava quais os benefícios que a atividade poderia trazer para ele, por exemplo, quais habilidades instigadas durante o processo. Por fim, foram investigadas as dificuldades encontradas para a resolução do caso.

A entrevista, realizada com os professores, visava investigar suas concepções sobre a EEEC a partir da experiência em gerir a atividade. Buscava a percepção frente aos casos construídos, as possíveis contribuições da atividade para os alunos e para sua prática pedagógica, bem como, as dificuldades encontradas pelos professores durante a aplicação da EEEC. Como forma de registro foi utilizada a gravação em áudio seguida de transcrição. Essas transcrições foram retornadas aos professores para que os dados fossem validados, permitindo ajustes nos pontos que eles julgassem necessários. 
A partir de leituras flutuantes do corpus de análise construído, foi possível notar mensagens significativas que nos remetiam a temas relevantes para o ensino e que apareciam com uma frequência considerável. Ademais, esses aspectos iam ao encontro da questão de pesquisa e dos objetivos deste estudo. Desta forma, optou-se pela metodologia Análise de Conteúdo, seguindo os preceitos de Bardin (2011).

\section{Resultados e discussão}

O questionário foi respondido por 65 alunos. Para a análise, no entanto, foram considerados apenas os questionários da turma da professora Carla, respondido por 25 estudantes. Os alunos também receberam nomes fictícios. Justifica-se a escolha dessa turma por apresentar um número maior de questionários respondidos. A entrevista foi realizada com os três professores. As respostas dos três foram consideradas para a análise.

Os resultados, como um todo, estão apresentados em quatro grandes tópicos: os casos construídos, as possibilidades da EEEC, os desafios da EEEC e as contribuições da aplicação da EEEC para o professor.

\section{Os casos construídos}

Cada professor escolheu o número de casos que seria elaborado e aplicado em sala de aula. A professora Regina optou pela construção de dois casos, já os professores Pedro e Carla construíram apenas um caso cada um. Assim, o número total de casos envolvidos na pesquisa foram quatro. Com relação aos temas trabalhados nos casos, a professora Regina, que optou pela construção de duas narrativas, discutiu em um dos casos o consumo de bebidas alcóolicas por adolescentes e os efeitos dessa substância no organismo; no outro caso, abordou o tema alimentação com foco para os hábitos alimentares.

Os outros dois professores, que optaram pela construção de apenas um caso, tiveram como tema geral da narrativa também a alimentação; todavia, o caso do professor Pedro teve como foco os hábitos alimentares e a valorização do corpo perfeito pela sociedade e o caso da professora Carla abordou o consumo e a produção de alimentos embutidos, com destaque para os conservantes e aditivos alimentares.

\section{Possibilidades da EEEC}

O tópico possibilidades da EEEC para a Educação Básica, retratado pelos sujeitos desta pesquisa, está organizado em três categorias: (a) dinâmica da atividade; (b) estímulo ao desenvolvimento de habilidades; (c) abordagem de conceitos científicos.

\section{a) Dinâmica da atividade}

Essa categoria gerou três subcategorias, apontadas na fala dos professores e de vários estudantes. São elas: participação ativa do estudante, trabalho em grupo e aproximação com a realidade do estudante. 
A percepção de professores e alunos do ensino médio ...

\section{Participação ativa do estudante}

Professores e estudantes apontaram que a atividade EEEC permite que o estudante, em sala de aula, participe de forma mais ativa e crítica. Exemplifica-se a seguir:

Penso que a estratégia Estudo de Caso difere do tradicional no sentido que possibilita aos alunos uma participação crítica, consciente, enquanto cidadãos ativos na sociedade. [Carla - Professora]

A capacidade em chegar a uma tomada de decisão frente a problemas, pra mim foi a mais importante, devido a nós alunos termos feito tudo sozinho. [Paula - Estudante]

Considerando o ensino sob o tripé educador, educando e conhecimento, é necessário que o educando tenha uma posição mais relevante, a qual deve ser reconhecida e posta em ação pelo educador. Para Azevedo (2010), no momento em que há valorização do aluno, em sala de aula, ele passa de mero observador e receptor de conhecimento, para um sujeito em ação em sala de aula, constituindo seu processo de aprendizagem. A EEEC apresenta um caráter investigativo que permite que o estudante tenha uma conduta mais expressiva no ambiente escolar.

Para Herreid (2004), a leitura, a discussão e o desafio são aspectos presentes no pensamento crítico. Todavia, esse autor reconhece que não é uma competência fácil de se instigar no espaço escolar, sendo necessário que os docentes conheçam o seu real significado. Diante disso, temos a EEEC defendida pelo autor como uma ótima proposta para o desenvolvimento deste pensamento, pois traz em seu formato questões incompletas que levam o estudante a levantar hipóteses, a buscar informações e fazer previsões.

\section{Trabalho em grupo}

A EEEC permite ser adotada em diferentes formatos: o expositivo, o individual, o de discussão e, por fim, o trabalho em grupo (HERREID, 1998). Este último formato, adotado nesta pesquisa, foi considerado como um aspecto positivo por professores e estudantes. Para estes diferentes sujeitos, esse formato estimula as discussões entre os estudantes e, consequentemente, há troca de opiniões. Diante disso, a compreensão de conhecimentos é facilitada, como pode ser notado na seguinte fala:

A maioria [dos alunos] pesquisou, trabalhando juntos, e isso mudou a postura deles. O trabalho em equipe é bom porque às vežes, quando o aluno pergunta ao professor, ele explica e esse continua não entendendo; já o colega da mesma faixa etária fala de um jeito que o outro entende. [Regina - Professora]

Moraes, Ramos e Galiazzi (2006) defendem que esse formato seja mais utilizado em sala de aula e destacam a necessidade de que os alunos filiem-se de qualidades pouco valorizadas no ensino, como: a solidariedade, o respeito e a compaixão. Qualidades que podem ser formadas a partir da compreensão dos indivíduos, das diferenças e dos direitos iguais, que este contexto de trabalho em equipe permite desenvolver. Os autores destacam ainda que o aprendizado é maior no período de discussão em que cada equipe irá definir o que aprendeu. 


\section{Aproximação com a realidade do estudante}

A contextualização não é um processo simples. O que vemos na tentativa dos professores, em geral, é a exemplificação. Lufti (2005) relata que, ao praticar erroneamente a contextualização, os docentes se isentam de discutir questões sociais, éticas, ambientais; de problematizar os tópicos do conteúdo específico com os assuntos em pauta, contribuindo para a alienação de seus estudantes. Para esse autor, o real sentido de contextualizar é entender como essas questões se encontram em nosso dia-a-dia.

A EEEC pode contribuir para essa contextualização visto que "um bom estudo de caso é o veículo por meio do qual uma parte da realidade é trazida para a sala de aula" (LAWRENCE, 1953 apud GRAHAM, 2010, p. 37). Segue a fala de uma professora:

Ponto positivo [da EEEC] é essa questão de relacionar o conteúdo com a vida, com o cotidiano, enxergar que a Química não está só lá, nas estruturas, nas fórmulas, mas que ela está presente no nosso dia a dia. [Carla - Professora]

Herreid (2004) destaca que a EEEC pode ser trabalhada nas disciplinas específicas, abordando a vivência do estudante e retratando uma questão social. Para isso, essa questão deve ser discutida a partir de uma relação com o saber específico, deve instigar a reflexão do aluno, de forma que esse vínculo tenha significado para ele. Alguns trabalhos têm sido desenvolvidos abordando a EEEC a partir de temas contextualizados na Educação Básica, mostrando que é um processo satisfatório para discussão de questões mais atuais e sociais. Como exemplo, temos o trabalho de Silva, Oliveira e Queiroz (2011), que discute, como tema central do caso, a poluição de ambientes aquáticos; e, ainda, o trabalho de Brito e Sá (2010), que retrata em seu caso sobre os biocombustíveis. Em ambos os trabalhos pode ser notado a possibilidade da EEEC de envolver, a partir de um tema central próximo da realidade, questões éticas, sociais, econômicas e políticas necessárias ao Ensino das Ciências.

\section{b) Estímulo ao desenvolvimento de habilidades}

$\mathrm{Na}$ opinião de professores e estudantes, a EEEC é uma atividade que dá condições para que diferentes habilidades sejam instigadas. As habilidades citadas por esses sujeitos foram: leitura, pesquisa, escrita, interpretação, argumentação, criatividade, tomada de decisão, raciocínio, comunicação oral e solução de problemas. As habilidades citadas convergem para aquelas que são reconhecidas pelos documentos oficiais, como PCN, OCN e ENEM, enquanto essenciais para a formação humana dos alunos. Outros trabalhos que discutiram a aplicação da EEEC na Educação Básica e a percepção dos alunos envolvidos reforçam o estímulo ao desenvolvimento de habilidades importantes citadas neste artigo (BRITO; SÁ, 2010; SÁ, 2006; SILVA; OLIVEIRA; QUEIROZ, 2011; SOUZA; ROCHA; GARCIA, 2012). Os trabalhos de Sá (2006) e Brito e Sá (2010) dão um enfoque maior para as habilidades argumentativas, mostrando como a EEEC pode estimular o processo de argumentação.

Durante a resolução do caso, o discente necessita mobilizar conhecimentos e informações, levantar hipóteses, analisar criticamente suas possíveis alternativas, até chegar a uma tomada de decisão. Para Perrenoud (1999), este contexto é muito propício ao desenvolvimento de habilidades pelos alunos. 
A percepção de professores e alunos do ensino médio ...

Para Maia (2009), no ensino de Ciências deve-se contemplar mais o "saber como" do que o "saber o quê". Para isso, é necessário promover situações em que o aluno busque suas próprias informações e saiba onde e quando aplicá-las. Atividades investigativas podem possibilitar tais atitudes. Desta forma, o sujeito aprenderá conceitos oportunos e, ainda, mobilizará habilidades necessárias para a formação de um cidadão mais ativo.

\section{c) Abordagem de conceitos científicos}

Os professores e estudantes destacam que a EEEC permite a abordagem de diferentes conhecimentos científicos. Nesta atividade, esses saberes devem estar atrelados a temas mais polêmicos e próximos da realidade do estudante. Devem, ainda, englobar questões éticas, sociais, culturais, ambientais, econômicas e políticas, quando possíveis. Desta forma, estará dando condições para que o estudante utilize desse conhecimento para entender e se manifestar no mundo. Segue a fala de uma estudante: "Esta atividade me levou a exercitar mais men pensamento químico, e tentar colocar a Química em tudo que realizo”. [Taís]

Como exemplo de conhecimentos abordados pelos alunos, destacamos aqui os retratados na narrativa "O Caso da Embutlar". A partir da problemática envolvendo os aditivos e conservantes alimentares, os alunos detalharam a produção dos alimentos embutidos. Alguns grupos discutiram sobre o processo de defumação, citaram substâncias orgânicas presentes na fumaça dos defumadores, como: fenóis, cetonas, aldeídos, dando destaque para os hidrocarbonetos benzopirenos. Os alunos apresentaram a fórmula molecular e estrutural, as propriedades químicas e a toxicidade dessas substâncias.

Alguns grupos abordaram também os conceitos relacionados à termoquímica, apontando reações de formação e os valores de entalpia de algumas substâncias. Discutiram sobre a relação da cinética química e os processos envolvidos em uma indústria. Frente ao processo de conservação e o uso de aditivos químicos nos alimentos embutidos, debateram sobre os nitratos e nitritos e a formação das nitrosaminas, derivadas dessas substâncias.

\section{Desafios da EEEC}

Com relação aos desafios destacados por professores e alunos, sobre a vivência com a EEEC, foram organizadas duas categorias para discussão: tempo e recursos.

\section{Tempo}

Dentre os obstáculos para a aplicação de propostas diferenciadas em sala de aula, a falta de tempo tem sido um dos mais destacados pelos professores. Essa justificativa mostrase coesa, já que o sistema de ensino brasileiro é estruturado em currículos extensos, com uma grande listagem de conteúdos descontextualizados, focados apenas na informação e memorização. Isso porque os programas de seleção apresentam ainda editais carregados de conteúdo (MALDANER, 2006). Segue a fala de uma professora: "O meu conteúdo atrasou um pouco, eles vão fazer PISM², então tem essa questão do conteúdo que está em defasagem”. [Carla - Professora]

\footnotetext{
${ }^{2}$ O Programa de Ingresso Seletivo Misto (PISM) é uma das formas de avaliação do programa de seleção - o vestibular - da Universidade Federal de Juiz de Fora (UFJF), MG, Brasil. O PISM é formado por três módulos, que acontecem no final de cada ano do ensino médio.
} 
A EEEC não é uma atividade tão simples, no que se refere à sua aplicação. Portanto, ela poderia ser realizada envolvendo outros educadores, ou seja: diferentes disciplinas poderiam permear a aplicação de um tema central, abordado em um caso, de forma que a compreensão dos conhecimentos de todas as áreas envolvidas fosse necessária para a solução de um único problema. Assim, o aluno ao solucionar o caso seria levado a compreender que os saberes de diferentes áreas estão relacionados entre si e não fragmentados como o ensino tradicional tende a reforçar. Neste formato, o número de aulas seria distribuído entre as disciplinas e, o mais gratificante, seria um desafio enriquecedor tanto para o aluno, quanto para os professores envolvidos.

No trabalho de Pierini et al. (2015), os autores investigam a possibilidade da utilização da EEEC para uma abordagem interdisciplinar no Ensino das Ciências, a partir da percepção de professores da Educação Básica envolvidos em um curso de formação continuada. Através de um caso que aborda a acidez dos refrigerantes, alguns apontamentos são levantados e, em geral, o estudo mostra que a EEEC tem real potencial para uma abordagem interdisciplinar, podendo ser mais uma forma significativa a ser trabalhada nas escolas pelos professores.

\section{Recursos}

Outro desafio apontado pelos professores é a aplicação da EEEC em uma escola na qual os recursos são escassos. Por exemplo, a falta de acesso à internet na escola para que os alunos pesquisem sobre o caso, já que muitos alunos não têm ainda acesso a esse recurso em casa.

Quando esses profissionais se posicionam fica mais enfatizada a necessidade de mudança e investimento nas escolas brasileiras. É necessário frisar que o êxito da EEEC, tal como outras propostas de ensino, está associado a outras variáveis, como a postura do professor, a estrutura da escola, a relação professor-aluno. Uma sugestão para a falta de recurso para a pesquisa é a produção ou organização, pelo professor, de materiais que amparem o estudante durante a resolução do caso. Como exemplos têm-se: reportagens, artigos científicos, capítulos de livros.

Foram destacadas aqui sugestões para superar os empecilhos citados pelos entrevistados; no entanto, não queremos desvalorizar as dificuldades encontradas pelos docentes, visto que fazem parte da realidade escolar e devem ser ressaltadas e problematizadas.

\section{Contribuições da aplicação da EEEC para os professores}

A iniciativa de levar esses três docentes a aplicarem uma atividade, para eles nova, na qual acreditamos ter potencial, tinha o intuito de conhecer a concepção desses profissionais sobre a EEEC. Isso porque esses sujeitos vivenciam e fazem parte da realidade das escolas públicas. Pretendíamos, também, contribuir para a formação desses professores, pois como afirmam Moraes, Ramos e Galiazzi (2006, p. 95):

Ao acreditar que as aprendizagens vão se dando a partir da participação direta do aluno nas atividades propostas pelo professor, nas discussões e nas avaliações, entende-se que a apropriação do conhecimento profissional do professor também ocorre desse modo. É a reflexão sobre a prática e análise cotidiana das ações desenvolvidas com os alunos que contribuem efetivamente para tomadas de consciência sobre as questões do ensinar e 
A percepção de professores e alunos do ensino médio ...

do aprender e, consequentemente, o conhecimento vai se tornando mais complexo, com condições de oferecer, cada vez mais, respostas aos problemas que vão se apresentando.

Assim, esperávamos que as concepções dos professores permitissem discussões importantes, como está sendo realizado, e que o minicurso proferido, a aplicação da atividade e o momento de entrevista pudessem instigar esses docentes a refletirem sobre a sua prática. Pois como destaca Carvalho (2010), não podemos apenas trazer aos professores propostas de ensino prontas, pelo contrário, devemos tornar o ambiente propício para uma "mudança didática" por parte desses profissionais. Além disso, o autor destaca que a reflexão sobre a atividade permite que o indivíduo pense sobre a sua conduta, levando-o a um processo de revisão do que realizou e aprendeu. Esse momento pode propiciar "um desapego que autoriza críticas e permite a descentralização, sendo, dessa maneira, uma atividade facilitadora na busca da reelaboração didática" (CARVALHO, 2010, p. 10).

Ainda na entrevista, questionamos os docentes sobre quais as contribuições que a vivência em trabalhar com a EEEC trouxe para a sua prática pedagógica. Regina destaca a necessidade do professor estar atualizado e adquirir novos conhecimentos para aplicar essa estratégia. A professora Carla menciona a importância do professor ter coragem para ousar, destacando um fato bem próximo da realidade dos professores da Educação Básica, o receio de realizar mudanças em sala de aula:

Eu achei muito inovador, eu nunca tinha aplicado um caso em sala de aula e muitas vezes a gente fica receosa com este tipo de trabalho, porque não sabe que retorno vai ter, se vai ser positivo ou negativo e às vezes o medo nos paralisa, mas a gente tem que romper com essas barreiras, porque se a gente ficar como educador pensando que uma coisa não dá certo, outra coisa não dá certo, então cada ideia que você tiver você não vai aplicar porque fica receoso de que não vai dar certo? Então eu penso que a gente precisa realmente tentar romper com as barreiras. E eu achei muito legal, foi uma experiência muito positiva para a minha prática profissional. [Carla - professora]

O professor Pedro ressaltou ainda, como uma contribuição importante, a melhor relação entre professor e aluno estabelecida em sala de aula. Além das contribuições citadas, destacamos que as duas professoras, participantes desta pesquisa, submeteram trabalhos referentes à EEEC para congressos que envolviam a área de Educação em Ciências e Educação em Química. Ambos os trabalhos foram aceitos no formato de comunicação oral.

A professora Carla, em parceria conosco, submeteu um trabalho ao IX Encontro Nacional de Pesquisa em Educação em Ciências (ENPEC), realizado em 2013, o qual foi aceito. A docente relatava sobre a experiência de aplicar a EEEC, discutida nesta pesquisa. Ela abordou o caso construído, bem como as soluções apresentadas pelos alunos.

A professora Regina submeteu um trabalho, em parceria com uma aluna do PIBID de Química da UFJF, para o II Simpósio Mineiro de Educação Química (SMEQ). O evento aconteceu em 2013. O trabalho retrata a aplicação da EEEC, no formato de Caso Simulado, e aborda o tema Cosmético, sob um enfoque CTS relacionado ao conteúdo de química orgânica.

$\mathrm{O}$ fato de os professores terem aproveitado a experiência para apresentar trabalhos permite-nos entender que houve uma reflexão, por parte desses sujeitos, sobre o uso da EEEC. Esse 
movimento por parte dos professores vai ao encontro de uma ansiedade de muitos estudiosos que defendem que a pesquisa não deve acontecer apenas nas IES. Os professores da Educação Básica também podem e devem se tornar pesquisadores da própria prática, sempre refletindo sobre a mesma. Este é um aspecto importante para a formação continuada desses docentes.

\section{Considerações finais}

O eixo central deste estudo foi a potencialidade da EEEC para o ensino de Química, na Educação Básica. O percurso dessa pesquisa permitiu que resultados significativos fossem alcançados dentro da realidade do contexto educacional estudado.

Diante do estudo realizado, evidenciamos que na percepção dos principais atores envolvidos no espaço escolar do Ensino Médio, a EEEC é um instrumento de ensino favorável. Afinal, como notado durante a discussão dos dados, os casos elaborados possibilitaram o enfoque de conhecimentos químicos pertinentes relacionados ao cotidiano do aluno. Ademais, a experiência em vivenciar a EEEC demonstrou ser satisfatória para os estudantes, trazendo contribuições significativas para a sua formação humana. Professores e alunos destacaram várias habilidades que, em conjunto, poderiam colaborar para a tão almejada formação cidadã. Quanto aos professores, esses foram unânimes em estabelecer que a experiência em aplicar a EEEC contribuiu significativamente para a sua prática pedagógica.

A partir dos desafios apontados pelos professores e estudantes, destacamos que a EEEC está interligada a outras variáveis que compõem o rol do espaço escolar. São exemplos: a atuação do professor, as condições da escola, a relação professor-aluno, o contexto educacional, dentre outras; visto que temos um ambiente de trabalho bem diversificado nas escolas de nosso país.

Espera-se que a partir da vivência no minicurso, na aplicação da EEEC e na participação na entrevista, os professores tenham refletido sobre o processo. Os docentes reconheceram que aspectos como a ênfase na participação ativa e crítica do aluno e o estímulo ao desenvolvimento de habilidades eram importantes ao ensino e que, a aplicação da EEEC, podia ser uma proposta instigadora dos mesmos. Assim, esperamos que essa atividade seja utilizada novamente pelos docentes, além disso, almejamos que esses aspectos citados anteriormente estejam mais presentes no cotidiano da sala de aula, não só na aplicação da EEEC, mas em diferentes propostas de ensino.

São necessários estudos que envolvam o professor da Educação Básica e que contribuam para a sua formação continuada, levando-o a refletir sobre sua prática pedagógica. No entanto, destacamos a pertinência desses estudos darem mais oportunidade para o professor se expressar e participar mais efetivamente. Afinal, corremos o risco de, através das pesquisas educacionais, discutir os problemas e alternativas para a educação, mas permanecer com uma lacuna entre o professor da Educação Básica e os pesquisadores. Ou ainda, que o professor da Educação Básica seja tratado apenas como um executor das pesquisas acadêmicas, não recebendo retorno dos resultados. 
A percepção de professores e alunos do ensino médio ...

\section{Referências}

AZEVEDO, M. C. P. S. Ensino por investigação: problematizando as atividades em sala de aula. In: CARVALHO, A. M. P. (Org.). Ensino de ciências: unindo a pesquisa e a prática. São Paulo: Cengage Learning, 2010. p. 19-34.

BARDIN, L. Análise de conteúdo. São Paulo: Edições 70, 2011.

BOGDAN, R. C.; BIKLEN, S. K. Investigação qualitativa em educação: uma introdução à teoria e aos métodos. Porto: Porto Editora, 1994.

BRASIL. Ministério da Educação. Matriz de referência para o ENEM 2009. Brasília, 20009. Disponível em: <http://download.uol.com.br/educacao/enem2009/novo_enem_ habilidades_2009.pdf>. Acesso em: 2 set. 2015.

BRASIL. Ministério da Educação e do Desporto. Orientação curriculares nacionais do ensino médio: ciências da natureza, matemática e suas tecnologias. Brasília, 2006. v. 2. - Ministério da Educação e do Desporto. Parâmetros curriculares nacionais do ensino médio: ciências da natureza, matemática e suas tecnologias. Brasília, 2002.

BRITO, J. Q. A.; SÁ, L. P. Estratégias promotoras da argumentação sobre questões sócio-científicas com alunos do ensino médio. Revista Electrónica de Enseñanza de las Ciencias, Vigo, v. 9, n. 3, p. 505-529, 2010. Disponível em: <http://reec.uvigo.es/ volumenes/volumen9/ART2_Vol9_N3.pdf>. Acesso em: 14 mar. 2016.

CARVALHO, A. M. P. Critérios estruturantes para o ensino das ciências. In: CARVALHO, A. M. P. (Org.). Ensino de ciências: unindo a pesquisa e a prática. São Paulo: Cengage Learning, 2010. p. 1-17.

CARVALHO, A. M. P.; GIL-PÉREZ, D. Formação de professores de ciências: tendências e inovações. 10. ed. São Paulo: Cortez, 2011.

GEHLEN, S. T.; MALDANER, O. A.; DELIZOICOV, D. Momentos pedagógicos e as etapas da situação de estudo: complementariedades e contribuições para a Educação em ciências. Ciência \& Educação, Bauru, v. 18, n. 1, p. 1-22, 2012. Disponível em: < http:// dx.doi.org/10.1590/S1516-73132012000100001>. Acesso em: 14 mar. 2016.

GRAHAM, A. Como escrever e usar estudos de caso para o ensino e aprendizagem no setor público. Brasília: ENAP, 2010. DIsponível em: <http://casoteca.enap.gov.br/ attachments/article/4/Separatta_cap3.pdf >. Acesso em: 15 mar. 2016.

HERREID, C. F. Can case studies be used to teach critical thinking? Journal of College Science Teaching, Arlington, v. 33, n. 6, p. 12-14, 2004.

Sorting potatoes for Miss Bonner. Journal of College Science Teaching, Arlington, v. 27, n. 4, p. 236-239, 1998.

. What is a case? Journal of College Science Teaching, Arlington, v. 27, n. 2, p. 92-94, 1997. 
LUFTI, M. Os ferrados e os cromados: produção social e apropriação privada do conhecimento químico. 2. ed. Ijuí: Unijuí, 2005. (Coleção Educação em química).

MACEDO, L. Situação-problema: forma e recurso de avaliação, desenvolvimento de competências e aprendizagem escolar. In: PERRENOUD, P. et al. (Org.). As competências para ensinar no século XXI: a formação dos professores e o desafio da avaliação. Porto Alegre: Artmed, 2002. p. 113-136.

MAIA, P. F. Habilidades investigativas no ensino fundamentado em modelagem. 2009. 239 f. Tese (Doutorado em Educação) - Faculdade de Educação, Universidade Federal de Minas Gerais, Belo Horizonte, 2009.

MALDANER, O. A. A formação inicial e continuada de professores de química. 3. ed. Ijuí: Unijuí, 2006.

MALDANER, O. A.; ZANON, L. B. Situação de estudo: uma organização de ensino que extrapola a formação disciplinar em ciências. In: MORAES, R.; MANCUSO, R. (Org.). Educação em ciências: produção de currículos e formação de professores. Ijuí: Editora Unijuí, 2004. p. 43-64.

MORAES, R.; RAMOS, M. G.; GALIAZZI, M. C. A epistemologia do aprender no educar pela pesquisa em ciências: alguns pressupostos teóricos. In: MORAES, R.; MANCUSO, R. (Org.). Educação em ciências: produção de currículos e formação de professores. 2. ed. Ijuí: Unijuí, 2006. p. 85-108.

PERRENOUD, P. Construir as competências desde a escola. Porto Alegre: Artmed, 1999.

PIERINI, M. F. et al. Aprendizagem baseada em casos investigativos e a formação de professores: o potencial de uma aula prática de volumetria para promover o ensino interdisciplinar. Química Nova na Escola, São Paulo, v. 37, n. 2, p. 112-119, 2015.

RITTER, J.; MALDANER, O. A. CTS na situação de estudo: desenvolvimento de currículo e formação de professores. Praxis \& Saber, Tunja, v. 6, n. 11, p. 195-214, 2015.

SÁ, L. P. A argumentação no ensino superior de química: investigando uma atividade fundamentada em estudos de casos. 2006. Dissertação (Mestrado em Ciências - Química Analítica) - Instituto de Química, Universidade de São Paulo, São Carlos, 2006.

SÁ, L. P.; QUEIROZ, S. L. Estudo de caso no ensino de química. 2. ed. São Paulo: Átomo, 2010.

SANTOS, W. L. P.; MORTIMER, E. F. Uma análise de pressupostos teóricos da abordagem C-T-S (Ciência-Tecnologia-Sociedade) no contexto da educação brasileira. Ensaio: pesquisa em educação em ciências, Belo Horizonte, v. 2, n. 2, p. 1-23, 2002.

SANTOS, W. L. P.; SCHNETZLER, R. P. Educação em química: compromisso com a cidadania. 4. ed. Ijuí: Unijuí, 2010. 
SANTOS, W. L. P. et al. Formação de professores: uma proposta de pesquisa a partir da reflexão sobre a prática docente. Ensaio: pesquisa em educação em ciências, Belo Horizonte, v. 8, n.1, p. 1-14, 2006.

SILVA, O. B.; OLIVEIRA, J. R. S.; QUEIROZ, S. L. SOS Mogi-Guaçu: contribuições de um estudo de caso para a educação química no ensino médio. Química Nova na Escola, São Paulo, v. 33, n. 3, p. 185-192, 2011. Disponível em: <http://qnesc.sbq.org.br/online/ qnesc33_3/185-RSA09110.pdf>. Acesso em: 14 mar. 2016.

SOUZA, R. B.; ROCHA, P. D. P.; GARCIA, I. T. S. Estudo de caso em aulas de química: percepção dos estudantes de nível médio sobre o desenvolvimento de suas habilidades.

Química Nova na Escola, São Paulo, v. 34, n. 4, p. 220-228, 2012. Disponível em: <http:// qnesc.sbq.org.br/online/qnesc34_4/08-PIBID-112-12.pdf >. Acesso em: 14 mar. 2016. 